\title{
Colostroterapia e aleitamento materno na prevenção da enterocolite necrotisante
}

\author{
Colostroterapy and breastfeeding in the prevention of necrotisant enterocolitis
}

Colostroterapia y lactancia materna en la prevención de enterocolitis necrotisante

Andressa da Rosa Bassan ${ }^{1 *}$, Priscila Kurz de Assumpção ${ }^{1}$ Andrieli Berger da Rosa ${ }^{3}$, Thais Costa Schutz ${ }^{2}$, Daiany Saldanha da Silveira Donaduzzi ${ }^{1}$, Fernanda Almeida Fettermann ${ }^{4}$.

\begin{abstract}
RESUMO
Objetivo: Identificar na literatura científica evidências da colostroterapia e aleitamento materno na prevenção da enterocolite necrotisante. Métodos: Revisão integrativa realizada na Biblioteca Virtual em Saúde e base de dados da Literatura Latino-Americana do Caribe em Ciências da Saúde. Como critérios de inclusão, optouse por produções que estivessem disponíveis na íntegra, com resumo na base de dados e idioma português e excluídos artigos que não responderam à questão de pesquisa. Foram encontradas 360 produções, sendo utilizadas 10 na realização do artigo. Resultados: Os resultados deste estudo evidenciaram que o aleitamento materno precoce e o uso da colostroterapia ainda nos primeiros dias de vida são um dos meios mais eficazes para a prevenção da enterocolite necrotisante. Conclusão: Os cuidados da enfermagem com o recémnascido com enterocolite necrotisante, ainda necessitam de aprimoramento para uma prática com êxito, sendo necessário conhecimento sobre a patologia, a fim de desenvolver e prestar uma assistência com qualidade e merecedora para os recém-nascidos.
\end{abstract}

Palavras-chave: Enterocolite, Recém-nascido, Leite materno.

\begin{abstract}
Objective: To identify in the scientific literature evidence of colostrum therapy and early maternal breastfeeding in the prevention of necrotising enterocolitis. Methods: Integrative review conducted at the Virtual Health Library and database of Latin American Caribbean Literature in Health Sciences. As inclusion criteria, we opted for productions that were available in full, with a summary in the database and Portuguese language and articles that did not answer the research question were excluded. 360 productions were found, 10 of which were used to produce the article. Results: The results of this study showed that early breastfeeding and the use of colostrum therapy in the first days of life are one of the most effective means for the prevention of CNS. Conclusion: Nursing care with the newborn with necrotizing enterocolitis still requires improvement to a successful practice, and knowledge about the pathology is necessary in order to develop and provide quality and deserving care for newborns.
\end{abstract}

Keywords: Enterocolitis, Newborn, Breast milk.

\section{RESUMEN}

Objetivo: Identificar evidencia en la literatura científica de la calostroterapia y la lactancia materna en la prevención de la enterocolitis necrotizante. Métodos: Revisión integradora realizada en la Biblioteca Virtual en Salud y base de datos de Literatura del Caribe Latinoamericano en Ciencias de la Salud. Como criterio de inclusión, optamos por producciones que estuvieran disponibles en su totalidad, con un resumen en la base de datos y en idioma portugués. y se excluyeron los artículos que no respondieron a la pregunta de investigación. Se encontraron 360 producciones, 10 de las cuales se utilizaron para producir el artículo.

\footnotetext{
${ }^{1}$ Faculdade Integrada de Santa Maria (FISMA), Santa Maria - RS. *E-mail: andressabassan@gmail.com

2 Universidade Federal de Santa Maria, Santa Maria - RS

${ }^{3}$ Unimed Santa Maria, Santa Maria - RS.

${ }^{4}$ Centro Universitário Internacional, Uruguaiana - RS.
} 
Resultados: Los resultados de este estudio mostraron que la lactancia materna temprana y el uso de calostroterapia en los primeros días de vida son una de las formas más efectivas de prevenir la enterocolitis necrotizante. Conclusión: La atención de enfermería al recién nacido con enterocolitis necrotizante, aún necesita mejoras para una práctica exitosa, requiriendo conocimientos sobre la patología, con el fin de desarrollar y brindar una atención de calidad y merecida al recién nacido.

Palabras clave: Enterocolitis, Recién nacido, Leche materna.

\section{INTRODUÇÃO}

Os recém-nascidos (Rns) prematuros são uma das indagações mais significativas associadas à assistência perinatal. As complicações acometidas no parto prematuro contribuem para aproximadamente cerca de $50 \%$ das mortes neonatais e está entre a principal causa de morte antes dos 05 anos de idade (NASUF AWA, et al., 2018). A taxa de prematuros cresce cerca de $1 \%$ ao ano em todo o mundo e as de mortalidade continuam altas nesta população. Além, disso, reflete as condições socioeconômicas e de saúde materna, à prematuridade se destaca como a primeira causa de óbitos em Rns, seguida pela asfixia, enterocolite necrotisante (ENC) e as malformações congênitas (GAIVA MAM, et al., 2015).

O aleitamento materno é uma estratégia fundamental de proteção e desenvolvimento do recém-nascido. Além de de suas funções nutricionais ele exerce um importante papel no fortalecimento da relação entre mãe e filho (SOARES JPO, et al., 2016). A colostroterapia, trata-se da utilização do colostro materno puro como uma terapia imunológica, onde não se encontra nenhuma função nutricional para os recém-nascidos prematuros e de baixo peso. O colostro caracteriza-se como o leite inicial produzido nas junções estreitas do epitélio mamário estão abertas, permitindo o transporte de seus muitos componentes protetores (LOPES JB, et al., 2018).

O colostro é rico em citocinas e outros agentes imunológicos que fornecem uma proteção bacteriana, inflamatória e imunomudulatória contra as infecções (SOARES JPO, et al., 2016). Dessa forma, também passam fatores de proteção presentes com maior concentração principalmente em mães com Rns prematuros, atuando em diferentes mecanismos, desde barreira local na qual impede a adesão de micróbios à mucosa até modulando a interação de citocinas facilitando a absorvência de fatores imunológicos pela própria mucosa bucal (NASUF AWA, et al., 2018).

A ENC caracteriza-se como uma síndrome clinico-patológica que se manifesta por meio de sinais e sintomas gastrointestinais e sistêmicos que pode causar necrose de coagulação do trato gastrointestinal (OLIVEIRA GSA, et al., 2016). Esta por sua vez representa a mais temida e letal emergência gastrointestinal nas Unidades de Tratamento Intensivo Neonatais (UTINs) com uma taxa de mortalidade variando de $01 \%$ a 08\% (BORBA GG, et al, 2014). Geralmente acontece em Rns a termo, mas estima-se que a doença venha a acometer de 05 a $15 \%$ dos prematuros de muito baixo peso e cerca de $07 \%$ dos Rns a termo internados nas UTINs (BORBA GG, et al., 2014).

Salienta-se que o enfermeiro, tem grande importância neste cenário, cabendo-lhes também a responsabilidade pela gestão do cuidado dos Rns. Dessa forma, deverá planejar suas ações por intermédio do processo de enfermagem, com a participação dos membros da equipe, para assim promover uma melhor qualidade na assistência dos RNs (BORBA GG, et al., 2014).

Diante do exposto, justifica-se a escolha por esta temática e sob esta perspectiva, elabora-se a seguinte questão norteadora: Quais as evidências na produção científica, acerca da colostroterapia e do aleitamento materno na prevenção da enterocolite necrotisante. Tendo como objetivo: Identificar na literatura brasileira evidências acerca da colostroterapia e aleitamento materno na prevenção da enterocolite necrotisante.

\section{MÉTODOS}

Trata-se de uma revisão integrativa com abordagem qualitativa. O estudo foi realizado através da Biblioteca Virtual em Saúde (BVS) e na base de dados da Literatura Latino-Americana do Caribe em Ciências da Saúde (LILACS) sendo utilizada a mesma estratégia de busca: "Enterocolite" AND "Recem-Nascido" AND "Leite Materno" como descritores de assunto. O levantamento bibliográfico foi realizado em julho de 2020. 
Como critérios de inclusão, optou-se por artigos que estivessem disponíveis na íntegra, com resumo na base de dados e idioma português. Foram excluídos artigos que não responderam a questão de pesquisa. $\mathrm{Na}$ busca realizada na BVS, encontrou-se inicialmente 351 estudos disponíveis, e na LILACS foram encontrados 9 artigos, totalizando em 360 artigos, sendo que ao final foram utilizadas 10 produções. A busca nas bases de dados e a análise dos estudos foram realizadas em julho de 2020 de forma duplo-independente, por dois autores da pesquisa (Figura 1).

Figura 1 - Fluxograma do processo de seleção duplo-independente dos artigos incluídos na revisão.

\section{Revisor A}

Artigos encontrados $(n=360)$

Artigos duplicados excluídos $(n=14)$

Artigos selecionados para leitura do título e resumo $(n=346)$

Artigos excluídos após leitura do título e resumo $(n=257)$
Revisor B

Artigos encontrados $(n=360)$

Artigos duplicados excluídos $(n=14)$

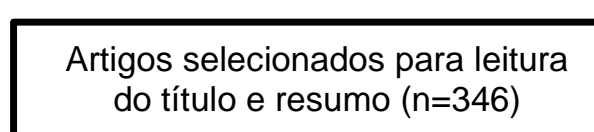

Artigos excluídos após leitura do título e resumo $(n=260)$
2 discordante

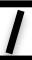

2 artigos excluídos pelo $3^{\circ}$ revisor

Artigos excluídos após leitura do texto completo:

Artigo não encontrado na íntegra $(n=19)$

Não responde à questão de pesquisa $(n=95)$

\section{Estudos incluídos para análise $n=10$}

Fonte: BASSAN AR, et al.,

Foi construído um quadro sinóptico, a fim de organizar e sintetizar as informações de maneira concisa, formando um banco de dados, abrangendo seguintes itens, Identificação (ID), título, autor/ano, método, objetivo e principais resultados. Os artigos foram identificados pela letra A de "artigo", seguida de uma numeração (A1, A2, A3, assim sucessivamente) conforme o Quadro 1.

Após a localização dos artigos, realizou-se a leitura dos resumos do material encontrado e, em seguida, a análise dos dados. Para a análise dos dados foi utilizado o método de Análise de Conteúdo, proposta por Minayo MCS (2013), cujos passos para a realização são divididos em três etapas.

Na primeira etapa, iniciou-se a exploração do material por meio da leitura flutuante. A segunda etapa consistiu-se da coleta dos dados, com a definição de categorias e a identificação das unidades de registro. $\mathrm{Na}$ terceira etapa, foi realizado a análise dos dados com o propósito de salientar as informações obtidas durante o estudo e, a partir dessas informações, concretizou-se a interpretação necessária para obter a resposta ao questionamento deste estudo.

\section{RESULTADOS}

As organizações das leituras ocorreram a partir da elaboração de categorias relativas ao tema, as quais surgiram após análise dos materiais avaliados. Os artigos analisados estão em no quadro 1, em ordem cronológica de acordo com seu ano de publicação. 
Quadro 1 - Quadro Sinóptico constituído das publicações analisadas.

\begin{tabular}{|c|c|c|c|c|c|}
\hline ID & Título & Autor/ano & Revista & Objetivo & Principais Resultados \\
\hline $\mathrm{A} 1$ & $\begin{array}{l}\text { Fatores associados à } \\
\text { enterocolite necrosante }\end{array}$ & $\begin{array}{c}\text { VIEIRA MTC, } \\
\text { LOPES JMA. } 2003 .\end{array}$ & Jornal de pediatria & $\begin{array}{l}\text { Avaliar as formas de apresentação } \\
\text { clínica da enterocolite necrosante } \\
\text { neonatal e os fatores associados à } \\
\text { doença. }\end{array}$ & $\begin{array}{l}\text { Os fatores associados significativamente à } \\
\text { enterocolite foram a ocorrência de apneia, } \\
\text { a progressão rápida da dieta e a } \\
\text { identificação do agente infeccioso. }\end{array}$ \\
\hline $\mathrm{A} 2$ & $\begin{array}{l}\text { Aspectos radiológicos } \\
\text { relevantes no } \\
\text { diagnóstico da } \\
\text { enterocolite necrosante } \\
\text { e suas complicações }\end{array}$ & $\begin{array}{l}\text { ALVARES BR, et al. } \\
2007\end{array}$ & RadiolBras & $\begin{array}{l}\text { Descrever os achados radiológicos } \\
\text { da enterocolite necrosante, } \\
\text { ilustrados com casos do serviço. }\end{array}$ & $\begin{array}{l}\text { O diagnóstico radiológico da enterocolite } \\
\text { necrosante realizado em todas as suas } \\
\text { etapas, contribui para uma conduta } \\
\text { terapêutica imediata, reduzindo as } \\
\text { complicações e aumentando a sobrevida } \\
\text { dos pacientes. }\end{array}$ \\
\hline A3 & $\begin{array}{c}\text { Enterocolite necrosante } \\
\text { em recém-nascidos de } \\
\text { um hospital de } \\
\text { referência em recife: } \\
\text { estudo epidemiológico }\end{array}$ & $\begin{array}{l}\text { ARAÚJO PM, et al. } \\
2008\end{array}$ & $\begin{array}{l}\text { Revenferm UFPE } \\
\text { online. }\end{array}$ & $\begin{array}{l}\text { Desenvolver um } \text { estudo } \\
\text { epidemiológico sobre enterocolite } \\
\text { necrosante entre recém-nascidos } \\
\text { de um hospital de referência em } \\
\text { materno-infantil de Recife, } \\
\text { Pernambuco, Brasil }\end{array}$ & $\begin{array}{l}\text { Diante da alta mortalidade associada à } \\
\text { doença, entre as recomendações } \\
\text { sugeridas, destacam-se a conscientização } \\
\text { do profissional sobre a importância da } \\
\text { semiótica, de examinar clinicamente o } \\
\text { recém-nascido e de modo repetido pela } \\
\text { variação rápida de quadro clinico. }\end{array}$ \\
\hline A4 & $\begin{array}{l}\text { Peculiaridades da } \\
\text { circulação mesentérica } \\
\text { em recém-nascidos e } \\
\text { suas implicações em } \\
\text { doenças } \\
\text { gastrintestinais do } \\
\text { período neonatal }\end{array}$ & $\begin{array}{c}\text { CHIA CY, FALCÃO } \\
\text { MC, } 2009\end{array}$ & Rev Paul Pediatria & $\begin{array}{l}\text { Descrever peculiaridades da } \\
\text { circulação mesentérica neonatal. }\end{array}$ & $\begin{array}{l}\text { O recém-nascido apresenta } \\
\text { peculiaridades de irrigação sanguínea } \\
\text { gastrintestinal. A dopplerfluxometria da } \\
\text { artéria mesentérica superior é um método } \\
\text { não invasivo que determina as condições } \\
\text { circulatórias no território intestinal. }\end{array}$ \\
\hline A5 & $\begin{array}{l}\text { Enterocolite necrosante } \\
\text { em recém-nascidos de } \\
\text { muito baixo peso em } \\
\text { uma unidade neonatal } \\
\text { de alto risco do } \\
\text { Nordeste do Brasil } \\
(2003-2007)\end{array}$ & $\begin{array}{l}\text { BRAGA TD, et al., } \\
2012\end{array}$ & $\begin{array}{l}\text { Rev. Bras. Saúde } \\
\text { Matern. Infant., }\end{array}$ & $\begin{array}{l}\text { Avaliar a incidência de enterocolite } \\
\text { necrosante (ECN), no período de } \\
2003 \text { a } 2007 \text {, em crianças nascidas } \\
\text { com muito baixo peso. }\end{array}$ & $\begin{array}{l}\text { Observou-se aumento significante do uso } \\
\text { de antibióticos, de nutrição parenteral, de } \\
\text { corticóide antenatal e do consumo de leite } \\
\text { materno e uma redução na média da idade } \\
\text { gestacional de } 2,4 \text { semanas entre } 2003 \text { e } \\
2007 \text {. }\end{array}$ \\
\hline
\end{tabular}




\begin{tabular}{|c|c|c|c|c|c|}
\hline ID & Título & Autor/ano & Revista & Objetivo & Principais Resultados \\
\hline A6 & $\begin{array}{l}\text { Avaliação dos fatores } \\
\text { perinatais que } \\
\text { interferem na incidência } \\
\text { de enterocolite } \\
\text { necrosante em recém- } \\
\text { nascidos de muito } \\
\text { baixo peso }\end{array}$ & $\begin{array}{l}\text { VIEIRA AA, et al., } \\
2013\end{array}$ & $\begin{array}{l}\text { RevBrasGinecol } \\
\text { Obstet. }\end{array}$ & $\begin{array}{l}\text { Avaliar os fatores perinatais que } \\
\text { interferem na incidência de } \\
\text { enterocolite necrosante (ECN) em } \\
\text { recém-nascidos (RN) com peso } \\
\text { menor que } 1.500 \mathrm{~g} \text {. }\end{array}$ & $\begin{array}{l}\text { O único fator materno que se mostrou } \\
\text { relevante para a incidência de ECN nos } \\
\text { RN de muito baixo peso avaliado foi a } \\
\text { presença de PE. O conhecimento desse } \\
\text { fato pode direcionar a equipe perinatal a } \\
\text { um cuidado mais criterioso em relação à } \\
\text { prevenção de ECN nesta população } \\
\text { específica. }\end{array}$ \\
\hline A7 & $\begin{array}{l}\text { Eficácia dos probióticos } \\
\text { na profilaxia de } \\
\text { enterocolite necrosante } \\
\text { em recém-nascidos } \\
\text { prematuros: revisão } \\
\text { sistemática e meta- } \\
\text { análise }\end{array}$ & $\begin{array}{l}\text { BERNARDO WM, et } \\
\text { al., } 2013\end{array}$ & $\begin{array}{c}\text { Sociedade Brasileira } \\
\text { de Pediatria. }\end{array}$ & $\begin{array}{l}\text { Elucidar os benefícios do uso de } \\
\text { probióticos na prevenção de } \\
\text { enterocolite necrosante (ECN) e de } \\
\text { suas complicações em recém- } \\
\text { nascidos prematuros. }\end{array}$ & $\begin{array}{l}\text { Em recém-nascidos prematuros, o uso de } \\
\text { probióticos é eficaz na profilaxia de ECN e } \\
\text { de suas complicações. }\end{array}$ \\
\hline A8 & $\begin{array}{l}\text { Enterocolite necrosante } \\
\text { neonatal: uma revisão } \\
\text { iconográfica das } \\
\text { alterações radiológicas }\end{array}$ & $\begin{array}{l}\text { PENHA D, et al., } \\
2013\end{array}$ & AvEnferm. & $\begin{array}{l}\text { Realizar uma breve análise } \\
\text { etiopatológica da enterocolite } \\
\text { necrosante }\end{array}$ & $\begin{array}{l}\text { De fato, o radiograma de abdómen é o } \\
\text { meio diagnóstico gold-standard para } \\
\text { diagnóstico da doença precoce e ativa, } \\
\text { através dos vários sinais radiológicos, bem } \\
\text { como para acompanhamento e previsão } \\
\text { de eventuais complicações decorrentes da } \\
\text { enterocolite necrosante. }\end{array}$ \\
\hline A9 & $\begin{array}{c}\text { Nutrição precoce de } \\
\text { neonatos prematuros } \\
\text { estáveis e pequenos } \\
\text { para a idade } \\
\text { gestacional: um ensaio } \\
\text { clínico randomizado }\end{array}$ & $\begin{array}{c}\text { ARNON S, et al., } \\
2013 .\end{array}$ & $\begin{array}{c}\text { Sociedade Brasileira } \\
\text { de Pediatria. }\end{array}$ & 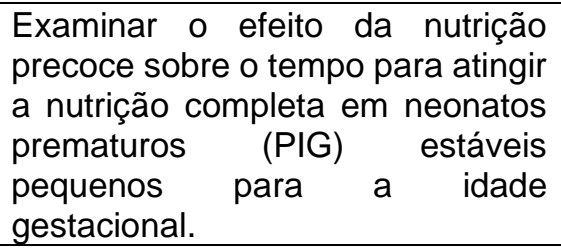 & $\begin{array}{l}\text { Nenhuma enterocolite necrosante (ECN) } \\
\text { foi comprovada em ambos os grupos de } \\
\text { estudo. A motilidade gástrica melhorou no } \\
\text { sétimo dia após o início da nutrição em } \\
\text { ambos os grupos de estudo, sem diferença } \\
\text { entre eles. }\end{array}$ \\
\hline A10 & $\begin{array}{c}\text { Em tempo: leite } \\
\text { humano é a estratégia } \\
\text { alimentar para prevenir } \\
\text { a enterocolite } \\
\text { necrosante }\end{array}$ & SCHANLERJ, 2015 & Rev Paul Pediatr. & $\begin{array}{l}\text { Identificar o desafio de atingir as } \\
\text { metas nutricionais de recém- } \\
\text { nascidos com extremo baixo peso. }\end{array}$ & $\begin{array}{l}\text { Tendo em vista que os novos fortificantes } \\
\text { do leite humano que não contêm proteína } \\
\text { bovina intacta estão agora disponíveis, } \\
\text { existe a possibilidade de eliminar a ECN } \\
\text { com uma dieta exclusiva de leite humano } \\
\text { da própria mãe. }\end{array}$ \\
\hline
\end{tabular}


Os artigos utilizados para análise, quanto ao ano de publicação estão classificados da seguinte forma: dentre os dez (100\%) artigos analisados na integra, observou-se que $10 \%(n=1)$ foi publicado no ano de 2003 , $10 \%(n=1)$ em 2007, 10\% (n=1) no ano de 2008, 10\% ( $n=1)$ em 2009, 10\% ( $n=1)$ artigo no ano de $2012,40 \%$ $(n=4)$ artigos no ano de 2013 e $10 \%(n=1)$ no ano de 2015. Em relação ao delineamento dos artigos selecionados, observou-se que em maior parte são do tipo quantitativo, $70 \%(n=7)$ artigos e $30 \%(n=3)$ estudos qualitativos.

Dentre os 10 autores que foram selecionados para o estudo, $05(50 \%)$ realizaram as pesquisas com análise da prevalência, características epidemiológicas e fatores de risco direcionados à enterocolite necrotisante e os outros $05(50 \%)$ sobre os resultados do uso de colostroterapia, aleitamento materno, probióticos, fórmulas e nutrição enteral precoce na prevenção da enterocolite necrotisante.

Dessas pesquisas, $50 \%(n=5)$ estudos fizeram uma análise dos pacientes internados na UTI de hospitais públicos e universitários que apresentavam diagnóstico de ENC, apontando suas causas e $50 \%(n=5)$ estudos foi por meio dos achados radiológicos e tipos de alimentações para a prevenção da ENC. Para fins de discussão, emergiram duas categorias, sendo elas: "Aleitamento materno precoce na prevenção da enterocolite necrotisante" e "Enterocolite necrotisante versus fórmulas alimentares e probióticos".

\section{DISCUSSÃO}

\section{Aleitamento materno e colostroterapia na prevenção da enterocolite necrotisante}

A ENC é uma das doenças primárias do trato gastrointestinal dos Rns pré-termo e uma invasão bacteriana da parede intestinal. Como uma de suas principais características aparece a distensão abdominal que pode evoluir para uma peritonite e assim podendo levar a um estado de choque (A1; A6). Formiga CKMR e Linhares MBM (2009), reafirma que a ENC é a doença gastrintestinal mais comum em Rns internados nas UTINs.

Na sua pesquisa Formiga CKMR e Linhares MBM (2009), mostra que a ENC vem sendo uma doença primária do trato gastrintestinal dos Rns e independentemente de todo os avanços na neonatologia, a ENC continua sendo uma das mais relevantes causas de morbidade e mortalidade dos Rns. Frente a isso, é necessário prestar um cuidado maior a essa população, uma vez que esta tem um histórico de alto índice de suspeição clínica para identificação oportuna de eventos desfavoráveis.

Acredita-se que a prematuridade é vista como um fator de risco para a enterocolite necrotisante, o aumento dessa vulnerabilidade é concedido ao grau de imaturidade intestinal referente as funções motora e digestiva, regulação da resposta inflamatória e modificação no padrão de colonização intestinal (A5). Formiga CKMR e Linhares MBM (2009), confirmam que os nascimentos de Rns prematuros é um acontecimento que normalmente gera alguma complicação de risco ao desenvolvimento.

Ainda, segundo Formiga CKMR e Linhares MBM (2009), mostra que a prematuridade é um dos fatores de risco mais significantes para o seu desenvolvimento, sendo sua ocorrência inversamente proporcional à sua IG e ao peso ao nascer. A origem da ENC ainda não está absolutamente esclarecida, mas a causa mais aceita refere-se à um processo mútuo entre três fatores predisponentes: prematuridade, isquemia e infecção.

Em sua pesquisa Formiga CKMR e Linhares MBM (2009) o recém-nascido prematuro, especialmente quando tratados em terapia intensive, apresenta um grande risco de desenvolver problemas nutricionais e de crescimento, isso se dá as alterações metabólicas causadas por vários processos patológicos e a fatores fisiologicos inerente a prematuridade vulneraveis aos danos infecciosos porque a imunidade está envolvida com a baixa formação de citocinas, pela redução da manifestação de moleculas de ligação nos neuttrofilos e sua explicação aos quimiottaticos. Os niveis de iunoglobulinas $\operatorname{lgM}$ e $\lg A$ são minios, e a criação desses anticorpos ainda é insuficiente, com isso o sistema imunologico está ainda mais comproettido durante todo o period neonatal.

O leite materno estabelece uma maior proteção por meio das característticas nutricionais, com isso, o impacto que o leite tem sobre algumas morbidades tem sido associalda a doses dependentes. Com isto, 
quanto maior é a quantidade recebida de leite materno e colosro nos primeiros dias de vida menor é o risco de novas comorbidades. O leite materno, além de nutrir ele também estará agindo em toda imunidade e flora intestinal do recem-nascido e se possivel assim evitando ao máximo o uso de fôrmulas alimentares (A5).

Segundo Nascimento MBR e Issler H (2004), o colostro é um fluido concentrado nas células alveolares desenvolvidos nos últimos meses de gestação e segregado logo nos primeiros dias depois do parto, assim sendo essencialmente abundante em imunoglobulina, peptídeos antimicrobianos entre outras moléculas, contendo elementos trópicos e algumas substâncias antiflamatórias. O leite é excepcionalmente complexo, abrange não somente quantidae de nutrientes, habilidades digestiva e metabólica do recén-nascido, mas também, elementos protetores que asseguram sua saúde, crescimento e seu desenvolvimento.

O colostro e o leite materno oferecem ao recém-nascido algumas substancias imunologicas para o seu crescimento que auxiliam a mucosa intestinal contra a invasão de alguns patogenos, incentivam a maturação epitelial e melhora a produção de algumas enzimas digestivas. As especialidaes antiflamattorias do colostro e também do leite materno aparecem por meio dos componentes soluveis e tambem ddos componentes celulares, assim as infecções frequentemente evitadas são pneumonia, bronquite, infecções do trato intestinal, entre outras (A9).

O leite materno assim como o colostro desempenha uma estável ação seletiva sobre a microflora e é o maior exemplo de como a dieta pode influenciar a microbiota, desde os dez dias de vida, o intestino da maioria dos Rns é colonizado com flora bacteriana predominantemente no leite materno (A5). Nunes LM (2015), demonstra que a dieta com o leite materno da própria mãe é fundamental papel na proteção contra os eventos relacionados as infecções, principalmente a enterocolite necrotisante.

A dieta com colostro e leite humano protege contra a retinopatia da prematuridade e contra sua forma mais grave, que é o descolamento da retina. Desta forma apoiam o pressuposto de que o leite humano tenha função antioxidante e que contenha fatores que afetam a angiogênese (A9). Nascimento MBR e Issler $\mathrm{H}$ (2004), reafirmam que com os elementos que o leite humano e o colostro materno fornecem, dentre eles o fator de crescimento epidérmico e a glutamina, venham a estimular a maturidade intestinal. Alguns antioxidantes do leite humano, tais como Vitamina E e o caroteno, ajudam a reduzir o estresse oxidativo.

Segundo Nascimento MBR e Issler H (2004), os ácidos graxos como o ômega 03 são fundamentais para que ocorra um desenvolvimento natural da retina, em especial nos Rns prematuros. Desta forma, esses lipídios, simultaneamente com outras substâncias antioxidantes, como vitamina E, B-caroteno e taurina, conseguiriam potencializar a proteção ofertada pelo leite materno e colostro. Já os oligossacarídeos do leite materno são açucares que compõe o terceiro componente mais prevalente no leite e no colostro, sendo agentes probióticos que, aparentemente, agem por meio do aumento da proliferação de espécies bifidobactérias benéficas que previnem a adesão de outras bactérias maléficas no epitélio intestinal (A9). Millani E, et al. (2009), ressalta que as bifidobactérias são mais tolerantes ao pH baixo intestinal dos recémnascidos alimentados com o leite materno.

Os fatores que auxiliam na resistência inata envolvem o pH luminal, enzimas, barreiras epiteliais entre outras. Os fatores que estão presentes no leite materno e no colostro exercem um papel protetor e reduzem a inflamação e posteriormente a invasão de espécies bacterianas no trato gastrointestinal (LOPES JB, et al., 2018). Demonstram ainda que o uso do leite humano tem efeito protetor e reduz a gravidade da enterocolite necrotisante, ressaltando ainda que o maior risco de enterocolite estão nos Rns alimentados exclusivamente com fórmulas (MILLANI E, et al., 2009).

Em sua pesquisa Millani E, et al. (2009), demonstra que com o uso leite materno provoca o desenvolvimento da flora intestinal, como bifidobactérias e lactobacilos, por intermédio da ação do que se acertou a chamar 'bifidus factor'. Esta atuação estabelece sua função de oligossacarídeos como a glicoproteína que inclui a glicose, galactose, frutose e nacetil galactosamina, que proporciona 0 desenvolvimento de bífidobactérias e lactobacilos. $O$ crescimento do acúmulo desses microorganismos no trato gastrintestinal é apontado como benéfico, ocasionando a síntese de moléculas que manifestam o efeito antibacteriano e antibiótico. 
É de suma importância que a equipe de enfermagem promova juntamente com os pais, o aleitamento materno precoce e o uso da colostroterapia para a prevenção não somente da enterocolite, mas também de outras doenças da prematuridade. Também, a parceria com outros profissionais abre para a enfermagem um campo inesgotável de possibilidades de atuação e contribui para um atendimento de forma integral e compartilhado.

\section{Enterocolite necrotisante versus fórmulas alimentares e proboóticos}

A incidência da ENC ocorre de 01 a 03 por 1.000 Rns nascidos vivos, sendo que boa parte são de prematuros com menos de $1.500 \mathrm{~g}$. Causada por vários fatores de risco dentre eles as mais importantes como a prematuridade e alimentação, o mecanismo fisiopatológico decorre da lesão da mucosa intestinal que conduz a uma isquemia levando a uma necrose (LOPES JB, et al., 2018). Millani E, et al. (2009), descreve a ENC como uma morbimortalidade afetando principalmente prematuros e baixo peso, assim como sendo caracterizada como uma infecção da mucosa que pode desenvolver uma isquemia levando a necrose.

Na sua pesquisa Millani E, et al. (2009), mostra que a enterocolite necrotisante é a emergência clínica predominante nos neonatos. A taxa de mortalidade é de aproximadamente $50 \%$ nos Rns com peso inferior a $1.500 \mathrm{~g}$. Com relação a etiologia continua mal esclarecida. A ENC atinge o trato gastrintestinal e, em alguns casos, pode ocorrer uma importante implicação sistêmica, a isquemia e algumas lesões por reperfusão podem ter um significativo papel, bem como os agentes infecciosos, apesar de que até o momento não ter sido descoberto uma possível explicação.

O mecanismo patogênico da ENC fundamentado em constatação clínica e histopatológica com a etapa inicial da doença, percebe-se ilhotas de isquemia e necrose na mucosa intestinal, antes mesmo da lesão extensa em toda parede do intestino, que seria esperado em caso de obstrução do fluxo sanguíneo (A4). Nunes LM (2015), reafirma a hipótese da isquemia intestinal associada a redistribuição do fluxo sanguíneo como patogênese da ENC, com isso teria início a resposta neurogênica avançando para uma redução no débito cardíaco levando a uma necrose intestinal e perfuração.

Com a modificação do fluxo sanguíneo, de suas respostas e de algumas condições específicas encontrase associadas à evolução do recém-nascido, principalmente no que diz respeito ao avanço da alimentação e ao progresso de quadros de intolerância relacionados a ENC (A3). Oliveira ND e Miyoshi MH (2013), reafirma que com o fluxo sanguíneo aponta poucas respostas já conhecidas frente a diferentes situações após o nascimento, mas que em sua grande maioria a progressão da alimentação é o maior fator.

Em sua pesquisa Oliveira ND e Miyoshi MH (2013), revelam que as pesquisas de avaliação do fluxo sanguíneo através do doppler exibem diminuição da aceleração do fluxo na artéria mesentérica superior que cursam com o atraso do crescimento, esta alteração permanece após o nascimento, no decorrer da primeira semana de vida. Na tentativa de distinguir antecipadamente os neonatos que sofrem de um estado de asfixia crônica e, deste modo, alcançar um marcador de risco para o surgimento da ENC (OLIVEIRA ND e MIYOSHI $\mathrm{MH}, 2013)$

Os probióticos são alguns micro-organismos vivos que são ofertados como suplementação alimentar que agem no intestino do organismo hospedeiro ajustando a flora bacteriana, com isso atuam aprimorando a permeabilidade gastrointestinal e ampliando a resistência da mucosa contra a penetração bacteriana, com isso melhoram a resistência da barreira intestinal e constituem substâncias bactericidas (LOPES JB, et al., 2018). Millani E, et al. (2009), reafirma que os probióticos são um conjunto de organismos favoráveis a melhorar o quadro da ENC a fim de combater a progressão da mesma.

Em seus estudos Millani E, et al. (2009), mostra que os probióticos são digeridos moderadamente no intestino delgado, impedem o aumento dos patógenos e incentivam a proliferação e o funcionamento de populações de bactérias desejáveis do cólon, afetando beneficamente o hospedeiro com o progresso da flora bifidogênica. Estes componentes influenciam constantemente no intestino grosso, sendo que os probióticos tornam-se considerados fontes naturais de energia para o desenvolvimento da flora bacteriana saudável do intestino (MILLANI E, et al., 2009). 
Alguns estudos vêm mostrando que a administração enteral de probióticos limita a incidência de casos de ENC, além de mostrar um menor tempo para realimentação oral e seu tempo de hospitalização (A8). Damasceno JR, et al. (2014), vem para reafirmar que em recém-nascidos principalmente aqueles nascidos prematuros a suplementação com os probióticos reduzem a incidência de casos graves da enterocolite necrotisante e são uma ferramenta adequada para a clínica pediátrica, com isso são necessários mais estudos para aprimorar a dosagem, além do tipo adequado de probiótico a ser utilizado.

Damasceno JR, et al. (2014), ainda descreve os probióticos como elementos de promoção do crescimento realizados por certos micro-organismos, são caracterizados como organismos vivos, que quando utilizados em quantidades apropriadas na alimentação, ofertam benefício à saúde do hospedeiro. Por serem microorganismos próprios de colonizar o trato digestivo por ligação ao epitélio intestinal, formando substâncias antimicrobianas, articulando a resposta imune e o metabolismo do hospedeiro (DAMASCENO JR, et al., 2014).

A nutrição enteral precoce está relacionada à maior tolerância ao leite materno e internação hospitalar mais curta, contudo foi feita uma observação sobre o início precoce e o progresso da nutrição enteral em neonatos principalmente os de baixo peso, demonstrando que isto pode predeterminar uma intolerância alimentar e um grande risco de enterocolite necrotisante (LOPES JB, et al., 2018).

Damasceno JR, et al. (2014), ressalta que o resultado da nutrição precoce em relação a nutrição tardia a respeito do tempo para a nutrição enteral e sobre a incidência da ENC demonstraram que os efeitos da alimentação completam precoce estão associados a menor necessidade de uma nutrição parenteral.

Cabe destacar que a a falta de conhecimento sobre os benefícios do aleitamento materno constitui um sério problema de saúde pública, sendo que na maioria das vezes não há uma preparação adequada durante o pré-natal e as nutrizes não têm as devidas orientações sobre a prática da amamentação exclusiva. Sendo assim, a promoção do aleitamento materno deve ser iniciada durante o pré-natal, dessa forma os profissionais da enfermagem devem proteger e apoiar esta prática e não deve ter apenas conhecimento empírico e habilidades técnicas (GUIMARÃES DC, et al., 2019).

Frente ao aumento da mortalidade relacionada à enterocolite necrotisante, sobressaem conscientização dos profissionais sobre a importância da alimentação certa dos Rns, a rápida identificação da doença e principalmente a necessidade de atualização sobre os assuntos. Além disso, principalmente incentivar as mães a adoção do aleitamento materno e a utilização da colostroterapia para uma maior proteção para a criança.

\section{CONSIDERAÇÕES FINAIS}

A realização deste estudo possibilitou constatar que o uso precoce do leite materno e o uso da colostroterapia é um dos principais fatores para a redução da ENC, recém-nascidos que não receberem uma quantidade adequada de leite materno tem mais possibilidade de desenvolver a doença. A ENC é considerada uma das maiores emergências gastrointestinais ocorridas principalmente em prematuros. Percebe-se que quanto mais prematuro e de menos baixo peso, maior é o risco da ocorrência da doença. A comunicação entre equipe e mãe deve ser clara e de fácil entendimento, a troca de conhecimento a aproximação com seus filhos, as dúvidas e inquietações devem ser sanadas por aqueles que estão sempre prestando os cuidados. Os achados neste estudo, apesar de bastante conclusivos, atentam para a necessidade da realização de novas pesquisas voltadas a temática abordada. Os cuidados da enfermagem com o recém-nascido com enterocolite necrotisante, ainda necessitam de aprimoramento para uma prática com êxito, sendo necessário conhecimento sobre a patologia, para desenvolver e prestar assistência com qualidade e merecedora para os recém-nascidos.

\section{REFERÊNCIAS}

1. ALVARES BR, et al. Aspectos radiológicos relevantes no diagnóstico da enterocolite necrosante e suas complicações. Radiol Bras, 2007; 40(2):127-130.

2. ARNON S, et al. Nutrição precoce de neonatos prematuros estáveis e pequenos para a idade gestacional: um ensaio clínico randomizado. J. Pediatr. (Rio J.) [online], 2013, 89(4):388-393. 
3. ARAÚJO PM, et al. Enterocolite necrosante em recém-nascidos de um hospital de referência em recife: estudo epidemiológico. Rev. enferm. UFPE on line, 2008; 2(3): 255-262.

4. BERNARDO WM, et al. 2013. Eficácia dos probióticos na profilaxia de enterocolite necrosante em recém-nascidos prematuros: revisão sistemática e meta-análise. J. Pediatr. (Rio J.) [online], 2013; 89(1):18-24.

5. BORBA GG, et al. fatores associados à morbimortalidade neonatal: um estudo de revisão, Saúde (Santa Maria), Santa Maria, 2014; 40(1):09-14.

6. BRAGA TD, et al. Enterocolite necrosante em recém-nascidos de muito baixo peso em uma unidade neonatal de alto risco do Nordeste do Brasil (2003-2007). Rev. Bras. Saúde Matern. Infant., 2012; 12(2):127-133.

7. CHIA CY, FALCÃO MC. Peculiaridades da circulação mesentérica em recém-nascidos e suas implicações em doenças gastrintestinais do período neonatal. Rev Paul Pediatr, 2009;27(2):204-10.

8. DAMASCENO JR, et al. Nutrição em recém-nascidos prematuros e de baixo peso: uma revisão integrativa, Ver. Soc. Bras. Enferm. Ped, 2014; 14(1):40:46

9. FORMIGA CKMR, LINHARES MBM. Avaliação do desenvolvimento inicial de crianças nascidas pré-termo, Rev Esc Enferm USP 2009; 43(2):472-80

10. GAIVA MAM, et al. Mortalidade neonatal: analise das causas evitáveis. Revenferm UERJ, Rio de Janeiro, 2015 mar/abr; 23(2):247-53.

11. GUIMARÃES DC, et al. Conhecimento da puérpera sobre amamentação na Atenção Básica. Revista Eletrônica Acervo Saúde, 2019; 18e107:1-7.

12. LOPES JB, et al. Colostroterapia: uma revisão de literatura, Demetra; 2018; 13(2); 463-476.

13. MILLANI E, et al. Efeitos da utilização de prebióticos (oligossacarídeos) na saúde da criança, Rev Paul Pediatr 2009; 27(4):436-46.

14. MINAYO MCS. O desafio do conhecimento: pesquisa qualitativa em saúde.13 ed. São Paulo, SP: Hucitec, 2013.

15. MOURA ERBB, et al. Investigação dos fatores sociais que interferem na duração do aleitamento materno exclusivo, Revista Intertox-EcoAdvisor de Toxicologia Risco Ambiental e Sociedade, 2015; 8(2):94-116.

16. NASCIMENTO MBR, ISSLER H. Aleitamento materno em prematuros: manejo clínico hospitalar, Jornal de Pediatria, 2004; 80(5).

17. NASUF AWA, et al. Oropharyngeal colostrum in preventing mortality and morbidity in preterm infants, Cochrame Database SystVer; 2018; 7(7).

18. NUNES LM. Importância do aleitamento materno na atualidade, Boletim Científico de Pediatria, 2015; 4(3).

19. OLIVEIRA GSA, et al. Prevenção da enterocolite necrotisante no recém-nascidos: revisão bibliográfica, IV seminário de enfermagem, 2016.

20. OLIVEIRA ND, MIYOSHI MH. Avanços em enterocolite necrotisante, Jornal de Pediatria, 2013; 81(1).

21. PENHA D, et al. Enterocolite necrosante neonatal: uma revisão iconográfica das alterações radiológicas. Rev Clin Hosp Prof Dr Fernando Fonseca, 2013; 2(1): 34-36.

22. RODRIGUES RG, OLIVEIRA ICS. Os primórdios da assistência aos recém-nascidos no exterior e no Brasil: perspectivas para o saber de enfermagem na neonatologia (1870-1903). Revista Eletrônica de Enfermagem, 2004; 6(2):286-291.

23. SCHANLERJ, 2015. Em tempo: leite humano é a estratégia alimentar para prevenir a enterocolite necrosante. Ver Paul Pedriatr, 2015; 33(2): 131-133.

24. SOARES JPO, et al. Amamentação natural de recém-nascidos pré-termo sob a ótica materna: uma revisão integrativa, Ver. CEFAC, 2016; 18(1):232-241.

25. VIANA TP, et al. Desenvolvimento cognitivo e linguagem em prematuros, AudiolCommun Res, 2014; $19(1): 1-6$.

26. VIEIRA MTC, LOPES JMA. 2003. Fatores associados à enterocolite necrosante, 2003; 79(3):159-164.

27. VIEIRA AA, et al. Avaliação dos fatores perinatais que interferem na incidência de enterocolite necrosante em recémnascidos de muito baixo peso. Rev Bras Ginecol Obstet, 2013; 35(8):363-7. 